\title{
Associative properties of a conditioned inhibitor as a function of age in kittens
}

\author{
NANCY K. DESS and S. STEFAN SOLTYSIK \\ University of California, Los Angeles, California
}

\begin{abstract}
The efficacy of conditioned inhibition in a novel conditioned stimulus/conditioned inhibitor (CS/CI) compound was tested in 6-, 10-, and 14-week-old kittens. The conditioned response was suppression of respiration elicited by a 5.1-sec CS paired with a brief, mild footshock. During original inhibitory training, a CI was presented $2 \mathrm{sec}$ after the onset of the CS, and the stimuli coterminated $3 \mathrm{sec}$ later without the shock. As previously reported, the CI trained in this paradigm is more potent in older kittens but passes a summation test in all age groups (Dess \& Soltysik, 1989). In the transfer test, the order of the CS and CI was reversed, so that the CI preceded the CS with no stimulus overlap. Transfer of inhibition to this new compound was virtually absent in the 6-week-old kittens and nearly perfect in the 14-week-old kittens. The CI alone (before CS onset) elicited a strong fear response in the youngest kittens, moderate fear in the 10-weekold group, and very little fear in the oldest group. The transferability of inhibitory training to a different temporal configuration of the CS and CI is absent at 6 weeks of age and fully developed 8 weeks later.
\end{abstract}

Fear conditioning generates conditioned stimuli (CSs) that allow animals to anticipate harm and thus avoid or escape from it. Learned inhibition of fear also organizes defensive behavior. Inhibitory conditioning yields safety signals, or conditioned inhibitors (CIs), which alleviate fear when no danger exists and protect acquired fear from extinction (Soltysik, 1985; Soltysik \& Wolfe, 1980; Soltysik, Wolfe, Nicholas, Wilson, \& Garcia-Sanchez, 1983). In addition, CIs may be the principal reinforcers for and motivators of avoidance responses (Gray, 1987). Studies of the ontogeny of inhibitory learning, then, bear not only on the maturation of fear-inhibitory mechanisms but also on developmental changes in the maintenance and efficiency of conditioned fear and in the acquisition of aversively motivated instrumental behaviors.

We previously described the acquisition of conditioned fear and its inhibition in kittens of 4,8 , or 12 weeks of age (Dess \& Soltysik, 1989). Two 5.1-sec CSs were paired with a brief, mild footshock. A 3.1-sec CI was trained in an unreinforced compound with one of the CSs; CS onset preceded CI onset by $2 \mathrm{sec}$. The dependent measure was respiratory amplitude suppression, an extremely reliable measure of conditioned fear in kittens and adult cats (Soltysik, Dess, Wilson, Matochik, \& Berg, 1988; Soltysik, Nicholas, \& Wilson, 1984; Soltysik \& Wolfe,

\footnotetext{
The authors wish to acknowledge help from $\mathbf{R}$. Jackson in running the experiments and processing the data. This study was supported by Program Project Grant HD 05958 and by Training Grant HD07032, both to the UCLA Mental Retardation Research Center, from the NICHD. S.S.S. is with the Mental Retardation Research Center; correspondence should be addressed to N. K. Dess, who is now at Occidental College, 1600 Campus Road, Los Angeles, CA 90041.
}

1980). Inhibition was defined as the extent to which the CI reversed the ongoing respiratory suppression elicited by the CS.

Neither the rate nor the asymptote of excitatory conditioning differed among the age groups. Asymptotic conditioned inhibition, on the other hand, increased significantly with age. In a summation test with the separately trained CS, the CI was as effective as it was in the original training compound for each age group. Thus, at no age did inhibition of fear by the CI depend on absolute preservation of the stimulus compound used during original training.

The present report concerns another test of the associative properties of the $\mathrm{CI}$ in these kittens, which was conducted at 6,10 , and 14 weeks of age. In this transfer test, the CS and CI were again presented in an unreinforced compound. However, CI presentation began prior to CS presentation; CI termination coincided with CS onset (see Figure 1). This stimulus arrangement provided two new pieces of information about the CI. First, the fear-eliciting properties of the CI were measured during its presentation alone, prior to the CS onset. Second, the ability of the CI to inhibit fear of the CS in a new temporal arrangement was assessed. Age differences in fear of the CI and transfer of inhibition to a new serial compound were both of interest.

Interpretation of the results of this transfer test is potentially confounded by group differences in the degree of original inhibitory conditioning. Therefore, a criterion of $15 \%$ inhibition of respiratory suppression by the $\mathrm{CI}$ at the end of training was used to eliminate poor learners from this analysis. This procedure allowed attribution of group differences in the transfer test to age-related differences in the fear-eliciting and fear-inhibiting properties of the 
$\mathrm{CI}$ rather than to differences in the asymptotic strength of the $\mathrm{Cl}$.

\section{METHOD}

\section{Subjects and Apparatus}

Twenty-five male and female kittens were supplied by the colony at the UCLA Mental Retardation Research Center; they were 4 weeks $(n=9), 8$ weeks $(n=9)$, and 12 weeks $(n=7)$ of age at the beginning of training. The kittens were from six litters, which remained intact throughout the experiment. Litters of 4 or more kittens were distributed across two of the experimental age groups so that subjects from at least three different litters were present in each age group. Water and dry food were continuously available, and canned cat food was available twice a day in the colony cages. Regular veterinary care, including routine feline vaccinations, was provided throughout the experiment.

The subjects were maintained on 12:12-h light:dark cycle, with light onset at 7:00 a.m. Training sessions were performed between 9:00 a.m. and 4:00 p.m., with each subject trained at approximately the same time every day.

During experimental sessions, the subjects were gently restrained in a Velcro-fastened canvas harness suspended from a metal frame. A treadmill under the harness allowed ambulation. A cat's head was held still by attachment of a cranial implant to the apparatus frame. The dental-cement implant and an abdominal EKG lead were prepared under general anesthesia I week prior to the stant of the experiment. Stabilization of the head was required for neurophysiological and pharmacological procedures that followed the present study or for which these subjects served as controls. Fortunately, head stabilization is not aversive for cats, because they normally stand, walk, and run without changing the position of the head.

The cranial implant is an excellent means of maintaining cats comfortably in our apparatus with no pressure points or pain. Between trials, our subjects are relaxed and some adult cats purr or nap. Moreover, when the cats' head position is fixed, the room's acoustics and the cats' visual angles-and therefore the perception of auditory and visual stimuli-vary little between subjects or over time. Fewer subjects and shorter experiments can provide significant results with such a preparation.

A thermistor probe was mounted on the cranial implant and positioned in front of the nares during the experimental sessions. The probe allowed measurements of respiratory amplitude and rate. Thoracography and diaphragmatic EMG, other methods of recording respiration, were rejected because they only detect chest movements or diaphragmatic respiration, but not both. The thoracographic record would have been distorted further by the snug-fitting harness.

The abdominal electrode and a reference electrode within the implant provided heart rate data. These data were used to compare the reliability of conditioned responding in several response systems and have been reported elsewhere (Soltysik et al., 1988). The low reliability of heart rate conditioned responses (CRs) relative to respiratory amplitude in kittens and adult cats prompted us to discontinue use of the EKG preparation.

The unconditioned stimulus (US) was a $300-\mathrm{msec}, 60-\mathrm{Hz}$ electric current passed between two electrodes. The electrodes were coated with electrode paste and attached with Velcro straps to the base of the tail and the plantar region of the left foot. A large electrode $\left(\mathrm{ca} 8 \mathrm{~cm}^{2}\right)$ on the tail served as the reference electrode, and the current density under it was low; a small electrode on the foot (ca $1 \mathrm{~cm}^{2}$ ) provided higher current density. Current intensity was adjusted to maintain a noticeable hindleg flexion, which tends to habituate over sessions; the US was incremented in 0.25 - $\mathrm{mA}$ steps from 2.0 to $3.5 \mathrm{~mA}$ over six sessions. A $2000-\mathrm{Hz}$ tone and a $10-$ $\mathrm{Hz}$ click, both $5.1 \mathrm{sec}$ long, served as the CSs. A 2-Hz sacral airpuff $\left(2 \mathrm{~g} / \mathrm{cm}^{2}\right)$ or revolution of a black-and-white striped cylinder approximately $50 \mathrm{~cm}$ in front of the subject (a rotor) served as the $\mathrm{CI}$; each was $3.1 \mathrm{sec}$ long.

The training apparatus was located in a large sound-attenuating chamber, which was continuously illuminated by a standard $25-W$ bulb. Masking noise was produced by an air valve mounted above the subject and a ventilation fan.

More information about this preparation is available in Wolfe and Soltysik (1981).

\section{Procedure}

Summary of training and test paradigms. The entire experimental protocol is shown in Table 1. Training began with an adaptation session, in which four stimuli were presented several times, each in random order. Conditioning consisted of 1 session of reinforced trials with tone and click CSs (CS1-US, CS2-US), and 10 sessions of intermixed reinforced and nonreinforced (CSI/CI) trials. The ratio of excitatory to inhibitory trials decreased from 10:5 to 6:8 over 8 sessions. This final ratio was retained for the rest of the experiment. Every session started with a reinforced trial, and no more than two successive identical trials were permitted. The intertrial interval varied from 1 to $3 \mathrm{~min}$.

Reinforced trials began with onset of the tone or click CS, which was followed $5 \mathrm{sec}$ later by the US. The CS-CI trials also started with the CS, but 2 sec later the CI was presented; the two stimuli ended 5.1 sec after CS onset without the US. Each subject received both types of CS-US trials but only one CI (rotor or airpuff) with only one of the CSs (tone or click). The tone or click combinations with rotor or airpuff were roughly balanced across subjects and age groups.

A summation test was conducted in Sessions 12 and 13. All kittens received three tone and three click CS-US trials. On the inhibitory trials, the $\mathrm{CI}$ was presented in serial compound with the CS that previously had never been compounded with a $\mathrm{Cl}(\mathrm{CS} 2 / \mathrm{CI}$ trials). Thus, subjects trained with a tone- $\mathrm{Cl}$ compound received click-Cl trials, and subjects trained with a click-CI compound received tone-CI trials.

Original trial types were used in Session 14. The transfer test was conducted in Sessions 15-18. In these sessions, the $\mathrm{CI}$ was presented alone for $3 \mathrm{sec}$ and was followed by a $5.1-\mathrm{sec}$ CS on eight unreinforced trials (CI-CS1). Six reinforced (CS1-US) trials were also given in each test session.

Figure 1 presents all types of trials used in acquisition, the summation test, and the transfer test. Note that all the inhibitory trials involve serial compounds: either the $\mathrm{CS}$ or the $\mathrm{Cl}$ precedes the onset of the other element of the compound by $2 \sec$ (CS-CI trials) or $3 \mathrm{sec}$ (CI-CS trials).

Respiratory amplitude: Measurement and computer-assisted data processing. To measure conditioned fear responses, a respiratory analogue of the conditioned emotional response (CER) was used. In our procedure, the amplitude of respiration, rather than the rate of appetitive behavior, constitutes the baseline whose suppression is taken as a measure of fear. The conditioned respiratory suppression (CRS) method has several important advantages over other methods. First, it does not require any preliminary training or weight reduction to establish a baseline behavior. This feature is advantageous for very young subjects in whom few learned baseline behaviors are available and for whom feeding should be unrestricted. Second, respiration does not change significantly with age. Whereas perinatal, preweaning, and postweaning feeding behaviors are very different both in motivation and in motor patterns, respiration remains basically the same. The early maturation of respiration allows for direct, valid comparisons across age groups.

In our CRS procedure, respiration is measured at 0.25 -sec intervals during each $25-\mathrm{sec}$ trial. The analogue signal from the nasal thermistor is converted into a series of digital scores representing respiratory peaks and troughs. The unedited data record includes 
Table 1

Types of Trials Used in Acquisition, Summation Test, and Transfer

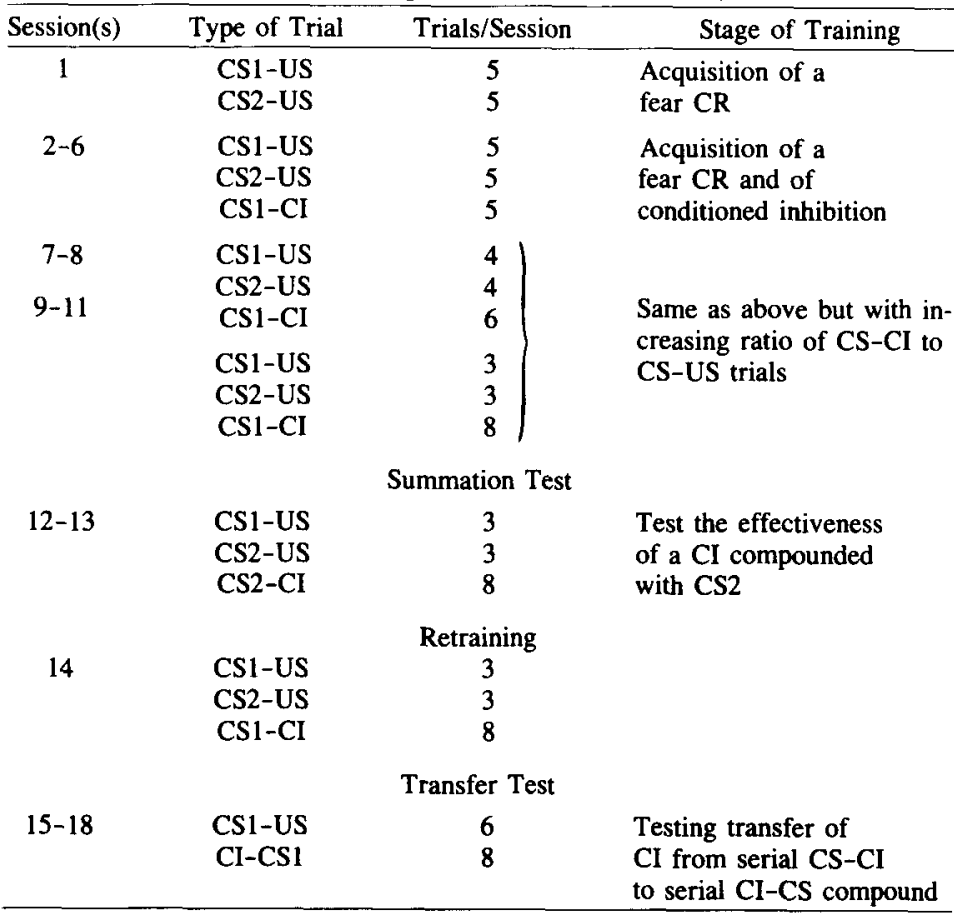

occasional artifacts due to vocalization or gross movements; small kinks in the respiratory cycle could be erroneously identified as a peak/trough sequence. Although the proportion of such artifactual data points in this study was small (ca $2 \%$ ), their inclusion would produce significant distortions in the respiratory record.

The average respiratory amplitude response from CS-US trials in the 14-week group is shown in Figure 2 for illustrative purposes. The scores are calculated relative to prestimulus average amplitude

\section{CS-US Acquisition Trial: (all phases)}

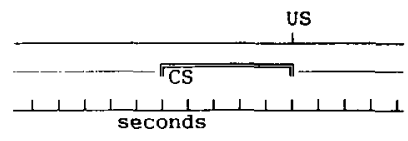

$$
\begin{gathered}
\text { CS-CI Inhibitory Trial: } \\
\text { (original training and } \\
\text { summation test) }
\end{gathered}
$$

$$
\begin{aligned}
& \text { Cl-CS Inhibitory Trial: } \\
& \text { (transfer test) }
\end{aligned}
$$
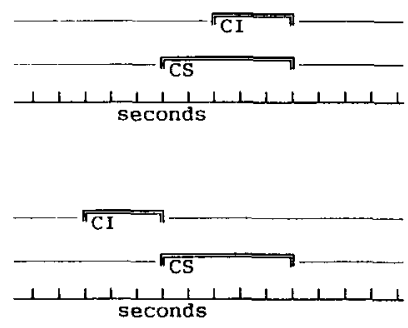

Figure 1. Three types of trials used in this study: (1) Acquisition trial (top), with 5.1-sec conditioned stimulus (CS) and .3-sec unconditioned stimulus (US) following a 5-sec interstimulus interval. (2) Inhibitory trial (middle), with the conditioned inhibitor (CI) beginning 2 sec after the CS onset and both stimuli terminating $5.1 \mathrm{sec}$ after the CS onset. In the acquisition phase of the experiment, only the CS1 was used in inhibitory trials; in the summation test, the CS2 was substituted without changing the temporal parameters of the compound. (3) Test trial (bottom), which started with the CI; 3 sec later, the CI was terminated and the 5-sec CS began. of relaxed breathing (taken as $100 \%$ ): the amplitude during the CS-US interval is subtracted from this pre-CS baseline. A response is given a positive value by inverting the scale so that $0 \%$ equals baseline respiratory amplitude and complete suppression of respiration equals $100 \%$. Increases in amplitude relative to baseline have negative values. Fear of the CS on CS-US trials and inhibition of fear on inhibitory trials (CS-CI or CI-CS) were calculated from data points at the late portion of the CS, when the response reached its asymptotic value (2.5-4.5 sec; see Figure 2).

In the transfer test, presentation of the $\mathrm{Cl}$ alone followed by the $\mathrm{CS}$ allowed measurement of CRS to the CI presented alone. Because the CI was shorter than the CS, the response was calculated from an earlier part of the stimulus, namely $1.5-3.0 \mathrm{sec}$. For comparison of fear of the CI to fear of the CS, the latter was also measured as suppression in the earlier part of the CS.

\section{RESULTS}

Acquisition data (Sessions 1-10) are fully reported elsewhere (Dess \& Soltysik, 1989). Transfer-test data were unavailable for two 6-week-old subjects, owing to computer failure. The $15 \%$ criterion for asymptotic inhibition eliminated 2 additional 6-week-old subjects and one 10-week-old subject from the sample. The final group sizes were: 6 weeks old, $n=5 ; 10$ weeks old, $n=8$; and 14 weeks old, $n=7$. At least three litters were represented in each of these groups. Inhibition differed significantly across the intact, unselected age groups (Dess \& Soltysik, 1989); in this selected sample of learners, however, the age groups did not differ significantly with respect to either inhibition at asymptote $[F(2,17)=1.85$, $p>.10$ ], or the effectiveness of the $\mathrm{CI}$ in the summation test $[F(2,17)=0.95, p>.10]$. Even a more powerful, mixed-design ANOVA with age and phase as vari- 


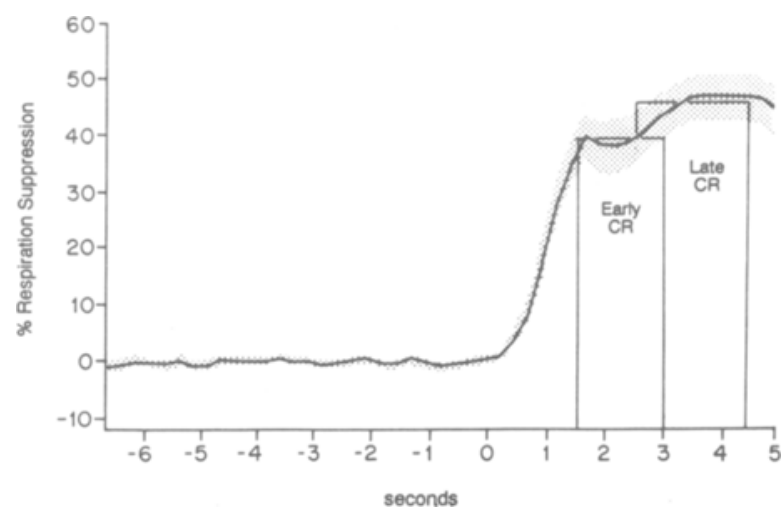

Figure 2. Conditioned respiratory suppression after excitatory conditioning in the 13-week-old kittens. Suppression before and during the conditioned stimulus (CS) (danger signal) is shown, with signal onset at Time 0 . Mean conditioned respiratory suppression (CRS) in 0.25-sec epochs is expressed as a percent of average pre-CS (baseline) respiratory amplitude; SEMs are depicted with stippling. The early and late responses were defined as average CRS from 1.5 to $3.0 \mathrm{sec}$ and from 2.5 to $4.5 \mathrm{sec}$ after CS onset, respectively.

ables yielded no significant effect of age $[F(2,17)=1.58]$ or phase $[F(1,17)=0.83]$, or a significant age $\times$ phase interaction $[F(2,17)=0.12$, ps $>.10]$.

The summation test, retraining, and transfer tests spanned seven sessions. CRS on the original-training trial types was examined for changes during this period. Analyses of respiratory suppression on tone-shock, clickshock, and unreinforced-compound trials yielded no significant effect for any trial type during this period (all ps $>.05$ ).

A preliminary analysis of the data from the transfer test established that the CS elicited comparable fear on reinforced trials in all age groups during the test phase $[F(2,17)=0.30, p>.10]$. Two issues were addressed with data from this test: First, did the CI inhibit fear of the CS when it was presented before rather than after CS onset? Second, did the CI itself have fear-eliciting properties? To answer the first question, inhibition scores were calculated for CI-CS trials during each of the four transfer sessions. The inhibition score is the difference between the response to the CS on reinforced CS-US trials and on unreinforced CI-CS trials, expressed as a percent of the response to the reinforced CS; thus, no inhibition equals $0 \%$ and total inhibition of the CRS equals $100 \%$. These data are presented in Figure 3. For young kittens, the safety signal in this new temporal arrangement was clearly less effective in inhibiting fear of the CS than it had been in the original training compound. In the oldest kittens, on the other hand, the CI was very nearly as effective when it preceded the CS as it had been during original training. A mixed-design ANOVA on data from the four transfer sessions showed a significant effect of age $[F(2,17)=7.37, p=.005]$. Neither the session effect $[F(3,51)=2.14]$ nor the age $\times$ session interaction $[F(6,51)=0.08]$ was significant $(p s>.10)$. Planned contrasts revealed that the 6-week-old group differed sig- nificantly from the 14-week-old group $[t(17)=3.83, p<$ $.05]$ and that each of these groups differed marginally from the 10-week-old group $[t \mathrm{~s}(17)=2.08$ and 2.06 , respectively, $p s<.10$ ].

Supplemental analyses compared inhibition by the airpuff and the rotor. The effectiveness of these two stimuli did not differ overall or as a function of age at the end of the original training or during the transfer test (all $F_{\mathrm{s}}<2$, ps $>.10$ ).

Transfer of inhibition was directly assessed in each kitten by expressing inhibition in the transfer sessions as a percentage of asymptotic inhibition for the original training compound. Stable estimates of the former were obtained by averaging inhibition over the four transfer sessions, since there was no session effect or age $\times$ session interaction. A transfer score of $0 \%$ indicates no transfer, and a score of $100 \%$ indicates perfect transfer. Means and SEMs for each age group are shown in Table 2. By this measure, transfer was nearly perfect in the older kittens but weak in the youngest kittens. An ANOVA yielded a marginally significant effect of age $[F(2,17)=2.93, p=$ $.08]$. Orthogonal contrasts showed that the older groups did not differ from each other $[t(17)=0.20, p>.10]$, but taken together, they differed from the youngest group $[t(17)=2.42, p<.05]$.

Fear of the CI was estimated by the CRS from $1.5 \mathrm{sec}$ after its onset to its termination (see Figure 2). The younger kittens clearly were more frightened by the CI presented by itself than were the older kittens. These age differences appeared early in, and were stable over, the first test session (see Table 3). An analysis of CRS on the first two trials yielded a highly significant age effect $[F(2,17)$ $=11.97, p<.001]$. An ANOVA comparing the first two trials with the last two trials of Test 1 yielded the same pattern of fear across age groups, and neither the effect of trial block nor the age $\times$ trial-block interaction was significant $(F s<2, p s>.1)$.

Data from all four transfer test sessions are presented in Figure 4; average CRS to the CS on reinforced trials

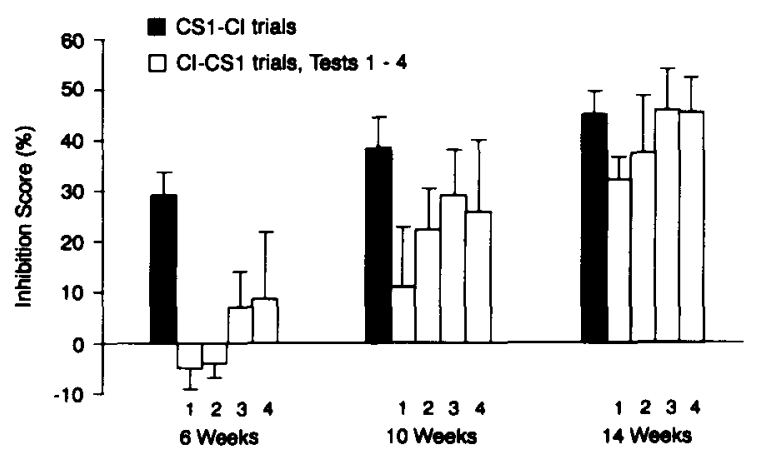

Figure 3. Inhibition of conditioned respiratory suppression (CRS) during the conditioned stimulus (CS) on conditioned inhibitor (CI)-CS trials in each of four transfer sessions, by age group. Inhibition on the original CS-CI trials is shown for comparison (shaded bars). 
Table 2

Transfer of Inhibition: Inhibition of Respiratory Suppression During the Transfer Test by Age, Shown as a Percentage of Inhibition at Training Asymptote

\begin{tabular}{cccc}
\hline Age & Median & $M$ & $S E M$ \\
\hline 6 weeks old & 23 & 2.4 & 7.3 \\
10 weeks old & 92 & 90.2 & 36.0 \\
14 weeks old & 95 & 97.6 & 20.2 \\
\hline
\end{tabular}

Note- $0 \%=$ no transfer; $100 \%=$ perfect transfer.

Table 3

Respiratory Suppression in Response to the Conditioned Inhibitor on the First Two Trials Versus the Last Two Trials in the First Transfer Test Session

\begin{tabular}{cccccc}
\hline & \multicolumn{2}{c}{ First Two Trials } & & \multicolumn{2}{c}{ Last Two Trials } \\
\cline { 2 - 3 } \cline { 5 - 6 } Age & $M$ & $S E M$ & & $M$ & $S E M$ \\
\hline 6 weeks & 37.7 & 8.2 & & 29.0 & 5.6 \\
10 weeks & 22.0 & 4.2 & 17.8 & 6.4 \\
14 weeks & 0.8 & 3.7 & & 5.8 & 2.4 \\
\hline
\end{tabular}

during the transfer test is shown for comparison. Age differences in fear of the CI persisted throughout testing.

A mixed-design ANOVA on data from the four transfer tests, with age and session as variables, yielded a significant effect of age $[F(2,17)=18.75, p<.001]$. Neither the session effect $[F(3,51)=1.94]$ nor the age $\times$ session interaction $[F(6,51)=1.02]$ was significant ( $p s>.10$ ). Planned comparisons showed that the 6week-old group differed significantly from the 10-weekold group $[t(17)=4.08]$, which in turn differed from the 14-week-old group $[t(17)=2.40]$.

Moderate violations of the assumptions for parametric tests exist in these data, including the small sample sizes, skewness in the inhibition scores of the 6-week-old group, and some heterogeneity of variance. To ensure that the effects found by the parametric tests were not due to a few extreme scores and inflated power, age differences in inhibition and fear of the $\mathrm{CI}$ were reanalyzed nonparametrically (omnibus Kruskal-Wallis tests and MannWhitney tests for pairwise comparisons). Every effect re-

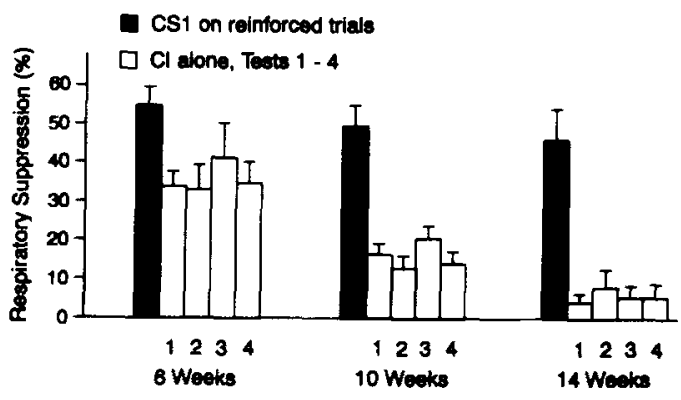

Figure 4. Conditioned respiratory suppression (CRS; fear) during the conditioned inhibitors (CIs) on CI-conditioned stimulus (CS) trials in each of four transfer sessions (Tests 1-4), by age group. Average CRS on CS-US trials is shown for comparison (shaded bars). ported above as significant was at least as significant by the equivalent nonparametric test.

Fear of the CI was greatest and inhibition of the fear of the CS by the CI was weakest in the youngest kittens; conversely, fear of the CI was weakest and inhibition greatest in the oldest cats. This pattern of results raises the possibility of a general inverse relationship between the fear elicited by the CI prior to CS onset and the CI's ability to inhibit fear during subsequent CS presentation. If such a relationship exists, the age difference in inhibition observed in the transfer test may be a by-product of an age difference in fear of the $\mathrm{CI}$ presented alone. This possibility was evaluated by correlating fear of and inhibition by the CI over all subjects and separately by each age group. The correlation was not significant overall or for any age group on the 1st test day or for four-session averages (all $p s>.05$ ).

\section{DISCUSSION}

Presentation of the $\mathrm{CI}$, which was trained in a CS-CI compound, before the CS yielded two differences among age groups. Fear of the CI was greater in younger kittens than in older kittens. This effect was not due to degree of original conditioning, because these age groups showed comparable asymptotic fear of the CS and inhibition by the CI. The occurrence of the CI alone was a novel event, raising the possibility that younger kittens were more neophobic than older ones. However, neophobia should abate with experience, and fear of the CI did not diminish significantly within the first session or over the four transfer test sessions.

The persistence of fear of the CI suggests that the fear was conditioned and maintained through contiguity with the CS. Fear of the CI could reflect excitatory withincompound conditioning (Williams, Travis, \& Overmier, 1986), but, given that direct excitatory conditioning does not differ across these ages, it seems unlikely that excitatory within-compound conditioning decreases with age. Alternatively, fear of the CI could reflect imperfect discrimination of the CSs and the CI. The stimuli may have been perceived configurally or "amodally" (Spear \& Molina, 1986) in the younger kittens, allowing generalization of excitation from the CSs to the CI. Amodal processing could have supported, for example, CRS to whatever stimulus came first in a trial. Though the use of auditory CSs versus multimodal CIs and serial onsets of the $\mathrm{CS}$ and $\mathrm{CI}$ should have facilitated discrimination between the stimuli, it may have done so only in older kittens.

The finding of excitatory properties in a well-trained inhibitor is not new. Coexistence of excitatory and inhibitory properties is well documented and has received considerable theoretical attention (cf. DeVito \& Fowler, 1987; Konorski, 1967; R. R. Miller \& Schachtman, 1985; Mowrer, 1960; Solomon \& Corbit, 1974; Williams et al., 1986). The present findings add to this literature by show- 
ing that an inhibitory conditioning procedure can yield either a CI with excitatory and inhibitory properties or a relatively pure inhibitor, depending on the age of the subjects.

The age groups also differed in the inhibitory effectiveness of the $\mathrm{CI}$ in the transfer test. Transfer of inhibition was greater in older kittens. The $\mathrm{CI}$ was most effective in the group least afraid of it, which could indicate that degree of transfer was a by-product of fear elicited by the CI: Once the CI had elicited fear, its ability to inhibit fear of the forthcoming CS could have been reduced. Our results do not support this interpretation. Fear of the $\mathrm{CI}$ and the inhibition by the $\mathrm{CI}$ were not inversely correlated when age was ignored or when it was held constant.

Transfer of inhibition, then, improved with age. Several age-dependent processes could be involved, including development of the associative mechanisms underlying conditioned inhibition. From a simple associative point of view, a CS is a positive (Rescorla \& Wagner, 1972) or excitatory (Konorski, 1948) stimulus associated with the US, and a CI is a negative or inhibitory stimulus associated with the absence of the US. Simple inhibitory association of a CI should transfer readily between stimulus arrangements; this view underlies conventional measures of conditioned inhibition (Rescorla, 1969). If we assume that learned inhibition of fear improves as the nervous system matures, older kittens should show more inhibition at asymptote and, therefore, in transfer tests. The present finding of greater inhibition in the transfer test in older kittens seems to favor this view. Because subjects in all age groups showed comparable asymptotic inhibition, however, any simple associative basis for differential transfer of inhibition should have been minimal. Furthermore, this view predicts at least some transfer of inhibition in the youngest kittens and some generalization decrement in the oldest kittens. Instead, these groups showed nearly $0 \%$ and $100 \%$ transfer of inhibition, respectively.

According to an alternative approach, a $\mathrm{CI}$ acquires an associative "structure' consisting of its spatiotemporal relationship to other events. It can include direct associations with CSs as well as hierarchical associations between the CI and CS/US relationships (Gallistel, 1990; Holland, 1985; Jenkins, 1985; Rescorla, 1985). This perspective predicts inhibitory transfer between some but not all stimulus arrangements. In our training procedure, for example, the CI cancels the otherwise-expected US. The CI follows the CS, so the CS may prompt retrieval of the $\mathrm{CI} / \mathrm{US}$ relation. To the extent that this CI's structure is incongruent with the rearrangement of stimuli in our transfer test, inhibition should fail to transfer. In addition, as the brain and its spatiotemporal encoding capacities mature, the simple associations of young animals should be supplanted by associatively complex CIs; further decreases in the transferability of inhibition should result. These predictions are clearly at odds with the excellent transfer of inhibition observed in our oldest kittens. Thus, neither of these theoretical views illuminates the nature of the age-related differences in inhibitory transfer observed in the present study.

The differences among the age groups in transfer of inhibition may have a nonassociative basis. Developmental changes in the perceptual processing of stimuli may play a role, as suggested above for age differences in fearfulness of the CI. Young kittens may have perceived the original CS-CI compound configurally or amodally, reducing the training procedure to a differential $(\mathrm{A}+, \mathrm{X}-)$ procedure. Generalization between the two CSs would have supported good inhibition by the $\mathrm{CI}$ in the summation test (Dess \& Soltysik, 1989), in which the temporal relationship of the CS and the $\mathrm{CI}$ were preserved. In the transfer test reported here, no comparable stimulus compound was presented, and inhibition failed. Older kittens, on the other hand, may have fully discriminated the CSs from the $\mathrm{CI}$ and thus treated the $\mathrm{CI}$ as a discrete signal for US omission in training, in the summation test, and in the transfer test reported here.

Developmental changes in short-term memory (J. S. Miller, Jagielo, \& Spear, 1989; Spear, 1979) also could contribute to differential transfer of inhibition. On CS-CI trials during acquisition and in the summation test, the CI was physically present when its effect on fear of the CS was assessed. In the CI-CS transfer test, $\mathrm{CI}$ onset and termination preceded CS delivery: when inhibition of fear of the CS by the CI was assessed, the CI was no longer present. Perhaps the "trace" of the CI was weaker in younger kittens. A determination of the validity of perceptual, memorial, or alternative associative explanations of the phenomena observed here requires further study.

In a related study, Holland and LaMarre (1984) trained rats in a simultaneous ( $\mathrm{CS}+, \mathrm{CS} / \mathrm{CI}-$ ) inhibitory conditioning procedure. This $\mathrm{CI}$ transferred well to another $\mathrm{CS}$ in a summation test, a finding consistent with results from kittens of all ages in our training procedure (Dess \& Soltysik, 1989). However, when Holland and LaMarre performed a serial CI-CS test similar to the present transfer test, no transfer of inhibition was observed. Poor temporal transfer concurs with our results from young kittens but conflicts with the good transfer observed among older kittens. If this discrepancy arose from the use of slightly different training procedures (true simultaneous vs. serial onset CS-CI compounds), it should have been apparent for kittens of all ages, and perhaps for the summation-test results. It was not. The discrepancy between the results of Holland and LaMarre's transfer test and ours, then, may reflect species differences in brain complexity. The frontal lobes and particularly prefrontal cortex, which has been implicated in conditioned inhibition (Brutkowski, 1965; Fuster, 1980) (although probably less so in nonaversively motivated behavior [Soltysik \& Jaworska, 1967]), are more highly evolved in cats than in rats. Thus, young kittens, with relatively immature prefrontal cortex (Kolb \& Nonneman, 1976), might be more "rat-like" in the transfer task than are older kittens. A comparative study of species with a lower encephalization quotient (Jerison, 1973) than that found in 
murines (e.g., insectivores) and species with a higher encephalization quotient than felines' (e.g., porcines or primates) may corroborate this hypothesis.

\section{REFERENCES}

Brutkowski, S. (1965). Functions of prefrontal cortex in animals. Psychological Review, 45, 721-745.

Dess, N. K., \& SoltysiK, S. S. (1989). Ontogeny of conditioned inhibition of conditioned respiratory suppression in kittens. Developmental Psychobiology, 22, 257-269.

DEVITO, P. L., \& Fowler, H. (1987). Enhancement of conditioned inhibition via an extinction treatment. Animal Learning \& Behavior, $15,448-454$.

Fuster, J. M. (1980). The prefrontal cortex. New York: Raven Press.

GALLISTEL, R. (1990). The organization of learning. Cambridge, MA MIT Press.

Gray, J. A. (1987). The psychology of fear and stress. Cambridge: Cambridge University Press.

Holland, P. C. (1985). The nature of conditioned inhibition in serial and simultaneous feature negative discriminations. In R. R. Miller \& N. E. Spear (Eds.), Information processing in animals: Conditioned inhibition (pp. 267-297). Hillsdale, NJ: Erlbaum.

Holland, P. C., \& LaMARRE, J. (1984). Transfer of inhibition after serial and simultaneous feature negative discrimination training. Learning \& Motivation, 15, 219-243.

Jenkins, H. M. (1985). Conditioned inhibition of keypecking in the pigeon. In R. R. Miller \& N. E. Spear (Eds.), Information processing in animals: Conditioned inhibition (pp. 327-353). Hillsdale, NJ: Erlbaum.

Jerison, H. J. (1973). Evolution of the brain and intelligence. New York: Academic Press.

Kolb, B., \& Nonneman, A. J. (1976). Functional development of the prefrontal cortex continues into adolescence. Science, 193, 335-336

KonORSKI, J. (1948). Conditioned reflexes and neuron organisation. Cambridge: Cambridge University Press.

KONORSKI, J. (1967). Integrative activity of the brain: An interdisciplinary approach. Chicago: University of Chicago Press.

Miller, J. S., Jagielo, J. A., \& Spear, N. E. (1989). Age-related differences in short-term retention of separable elements of an odor aversion. Journal of Experimental Psychology: Animal Behavior Processes, 15, 194-201.

Miller, R. R., \& Schachtman, T. R. (1985). Conditioning context as an associative baseline: Implications for response generation and the nature of conditioned inhibition. In R. R. Miller \& N. E. Spear (Eds.), Information processing in animals: Conditioned inhibition (pp. 51-88). Hillsdale, NJ: Erlbaum.

MOWRER, O. H. (1960). Learning theory and behavior. New York: Wiley.

Rescorla, R. A. (1969). Pavlovian conditioned inhibition. Psychological Bulletin, 72, 77-94.
ResCORLA, R. A. (1985). Conditioned inhibition and facilitation. In R, R. Miller \& N. E. Spear (Eds.), Information processing in animals: Conditioned inhibition (pp. 299-326). Hillsdale, NJ: Erlbaum.

Rescorla, R. A., \& Wagner, A. R. (1972). A theory of Pavlovian conditioning: Variations in the effectiveness of reinforcement and nonreinforcement. In A. H. Black \& W. F. Prokasy (Eds.), Classical conditioning II: Current research and theory (pp. 64-99). New York: Appleton-Century-Crofts.

Solomon, R. L., \& CoRBIT, J. D. (1974). An opponent-process theory of motivation: I. The temporal dynamics of affect. Psychological Review, 81, 119-145

SolTysiK, S. S. (1985). Protection from extinction: New data and a hypothesis of several varieties of conditioned inhibition. In R. R. Miller \& N. E. Spear, (Eds.), Information processing in animals: Conditioned inhibition (pp. 369-394). Hillsdale, NJ: Erlbaum.

Soltysik, S. S., Dess, N. K., Wilson, W. J., Matochik, J. A., \& BERG, S.(1988). Procedure and reliability of conditioned respiratory suppression. Animal Learning \& Behavior, 16, 177-184.

SoltYsik, S. S., \& JAwOrSKa, K. (1967). Prefrontal cortex and fearmotivated behaviour. Acta Biologiae Experimentalis, 27, 429-448.

Soltrsik, S. S., Nicholas, T., \& Wilson, W. J. (1984). Postnatal development of respiratory and vocal responses during aversive classical conditioning in cats. Pavlovian Joumal of Biological Science, 19, 169-181.

Soltysik, S. S., \& Wolfe, G. (1980). Protection from extinction by a conditioned inhibitor. Acta Neurobiologiae Experimentalis, 40, 291-311.

Soltysik, S. S., Wolfe, G., Nicholas, T., Wilson, W. J., \& GarciaSANCHEZ, J. L. (1983). Blocking of inhibitory conditioning within a serial conditioned stimulus-conditioned inhibitor compound: Maintenance of acquired behavior without an unconditioned stimulus. Learning \& Motivation, 14, 1-29.

SPEAR, N. E. (1979). Experimental analysis of infantile amnesia. In J. F. Kihlstrom \& F. J. Evans (Eds.), Functional disorders of memory (pp. 75-101). Hillsdale, NJ: Erlbaum.

SPEAR, N. E., \& Molina, J. C. (1986). The role of sensory modality in the ontogeny of stimulus selection. In N. Krasnegor, E. M. Blass, M. A. Hofer, \& W. P. Smotherman (Eds.), Perinatal development: A psychobiological perspective (pp. 83-110). Orlando, FL: Academic Press.

Williams, D. A., Travis, G. M., \& Overmier, J. B. (1986). Withincompound associations modulate the relative effectiveness of differential and Pavlovian conditioned inhibition procedures. Journal of Experimental Psychology: Animal Behavior Processes, 12, 351-362.

WolfE, G. E., \& SolTysik, S. S. (1981). An apparatus for behavioral and physiological study of aversive conditioning in cats and kittens. Behavioral Research Methods \& Instrumentation, 13, 637-642.

(Manuscript received April 3, 1991; revision accepted for publication September 17, 1992.) 